\title{
Intra-pancreatic tissue-derived mesenchymal stromal cells: a promising therapeutic potential with anti- inflammatory and pro-angiogenic profiles
}

Bashar Khiatah ${ }^{1 \dagger}$, Meirigeng $\mathrm{Q}^{1 \dagger}$, Weiting Du${ }^{1}$, Kuan T-Chen ${ }^{1}$, Kayleigh M. van Megen ${ }^{2}$, Rachel G. Perez ${ }^{1}$,

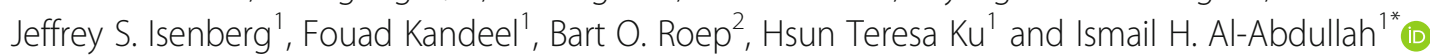

\begin{abstract}
Background: Human pancreata contain many types of cells, such as endocrine islets, acinar, ductal, fat, and mesenchymal stromal cells (MSCs). MSCs are important and shown to have a promising therapeutic potential to treat various disease conditions.

Methods: We investigated intra-pancreatic tissue-derived (IPTD) MSCs isolated from tissue fractions that are routinely discarded during pancreatic islet isolation of human cadaveric donors. Furthermore, whether proangiogenic and anti-inflammatory properties of these cells could be enhanced was investigated.

Results: IPTD-MSCs were expanded in GMP-compatible CMRL-1066 medium supplemented with 5\% human platelet lysate (hPL). IPTD-MSCs were found to be highly pure, with > 95\% positive for CD90, CD105, and CD73, and negative for CD45, CD34, CD14, and HLA-DR. Immunofluorescence staining of pancreas tissue demonstrated the presence of $\mathrm{CD}_{105^{+}}$cells in the vicinity of islets. IPTD-MSCs were capable of differentiation into adipocytes, chondrocytes, and osteoblasts in vitro, underscoring their multipotent features. When these cells were cultured in the presence of a low dose of TNF-a, gene expression of tumor necrosis factor alpha-stimulated gene-6 (TSG-6) was significantly increased, compared to control. In contrast, treating cells with dimethyloxallyl glycine (DMOG) (a prolyl 4-hydroxylase inhibitor) enhanced mRNA levels of nuclear factor erythroid 2-related factor 2 (NRF2) and vascular endothelial growth factor (VEGF). Interestingly, a combination of TNF-a and DMOG stimulated the optimal expression of all three genes in IPTD-MSCs. Conditioned medium of IPTD-MSCs treated with a combination of DMOG and TNF-a contained higher levels of pro-angiogenic (VEGF, IL-6, and IL-8) compared to controls, promoting angiogenesis of human endothelial cells in vitro. In contrast, levels of MCP-1, a pro-inflammatory cytokine, were reduced in the conditioned medium of IPTD-MSCs treated with a combination of DMOG and TNF-a.

Conclusions: The results demonstrate that IPTD-MSCs reside within the pancreas and can be separated as part of a standard islet-isolation protocol. These IPTD-MSCs can be expanded and potentiated ex vivo to enhance their antiinflammatory and pro-angiogenic profiles. The fact that IPTD-MSCs are generated in a GMP-compatible procedure implicates a direct clinical application.
\end{abstract}

Keywords: Mesenchymal stromal cells, Anti-inflammatory, Angiogenesis, Type 1 diabetes, TSG-6, NRF2, VEGF

\footnotetext{
*Correspondence: IAl-Abdullah@coh.org

${ }^{\dagger}$ Bashar Khiatah and Meirigeng Qi contributed equally to this work.

'Department of Translational Research and Cellular Therapeutics, Diabetes

and Metabolism Research Institute, Beckman Research Institute of City of

Hope, 1500 E. Duarte Rd, Duarte, CA 91010, USA

Full list of author information is available at the end of the article
}

(c) The Author(s). 2019 Open Access This article is distributed under the terms of the Creative Commons Attribution 4.0 International License (http://creativecommons.org/licenses/by/4.0/), which permits unrestricted use, distribution, and reproduction in any medium, provided you give appropriate credit to the original author(s) and the source, provide a link to the Creative Commons license, and indicate if changes were made. The Creative Commons Public Domain Dedication waiver (http://creativecommons.org/publicdomain/zero/1.0/) applies to the data made available in this article, unless otherwise stated. 


\section{Background}

Mesenchymal stromal cells (MSCs) have the potential for treating various diseases [1]. Currently, over 800 clinical trials involving MSCs have been registered (clinicaltrials.gov), the majority of which are focusing on the application of MSCs to diseases of the musculoskeletal and cardiovascular systems as well as autoimmune type 1 diabetes (T1D) [2, 3]. With respect to the treatment of diabetes with MSCs, some encouraging progress has been made. For example, intravenous injection of umbilical blood-derived allogeneic MSCs improved the function of pancreatic $\beta$-cells, reduced the incidence of diabetic complications, and led to insulin independence in some type 2 diabetic patients $[4,5]$. Autologous MSCs were used to treat individuals with T1D and lead to the preservation of C-peptide [6]. For this, bone marrow-derived MSCs were aspirated from iliac crest, a procedure with substantial discomfort [6]. Moreover, the administration of bone marrow-derived allogeneic MSCs together with pancreatic islets enhanced islet survival in diabetic non-human primates [7]. These studies employed fetal bovine serum in the MSC culture media, which is less desirable than media that lack animal proteins, pointing to a need for alternative culture and expansion strategies.

The mechanism by which MSCs protect human islets includes the expression of anti-inflammatory and proangiogenic genes $[8,9]$. Tumor necrosis factor alphastimulated gene-6 (TSG-6) induced by TNF- $\alpha$ has antiinflammatory properties [10-12]. Nuclear factor erythroid 2-related factor 2 (NRF2) is important in enhancing islet graft survival and function [13, 14]. Additionally, dimethyloxallyl glycine (DMOG), which targets prolyl-4hydroxylase to prevent the degradation of hypoxiainducible factor-1 $\alpha$ [15] and upregulate vascular endothelial growth factor (VEGF) [16], could be a possible conditioning factor for improving MSC function.

MSCs have been isolated from various sites including subcutaneous adipose tissue $[17,18]$, bone marrow $[19,20]$, skeletal muscle [21], umbilical cord blood [22], ocular limbus [23], and amniotic fluid [24]. Blood- and adipose-derived MSCs are widely investigated due to their accessibility, expandability, differentiability, and clinical applicability $[25,26]$. During the enzymatic digestion of the cadaveric pancreas, cells are liberated, together with islets, which can then be separated and characterized. In this study, we isolated MSCs from the otherwise discarded fractions of pancreatic tissue. These cells, designated as intra-pancreatic tissuederived (IPTD) MSCs, were cultured in a GMP-grade and xenoprotein-free culture medium containing human platelet lysate and conditioned in vitro with TNF$\alpha$ [27] and DMOG. Changes in gene expression, growth factor, and cytokine levels and angiogenic capacity after conditioning were determined. This study identifies a previously unappreciated fraction of the pancreatic digest as a useful source of anti-inflammatory and proangiogenic MSCs with possible clinical applications.

\section{Methods \\ Digestion of human pancreata from cadaveric donors}

Human cadaveric donor pancreata $(n=9)$ were obtained from an organ procurement organization. Cadaveric donors from which IPTD-MSCs were obtained averaged $33.8 \pm 3.1$ years of age, $29.8 \pm 1.8$ body mass index, and $5.1 \pm 0.1 \%$ hemoglobin A1c (Table 1). Pancreata from individuals with the criteria of Donation after Cardiac Death and $\mathrm{HbA} 1 \mathrm{c}>6.5 \%$ were excluded from this study. Islet isolation was carried out in a cGMP facility at City of Hope as previously described [28, 29]. Briefly, the pancreas was digested using collagenase supplemented with either thermolysin or neutral protease [28]. The digested pancreatic tissues were collected in $18250-\mathrm{mL}$ conical tubes and centrifuged at $182 \times g / 8^{\circ} \mathrm{C}$ for $3 \mathrm{~min}$. Pancreatic tissue was collected, washed, and purified in a cold COBE 2991 cell processor (COBE Laboratories Inc., Lakewood, CA, USA) [30]. Fractions of purified islets

Table 1 Characteristics of donors of pancreata used for islet and IPTD-MSC cell isolation

\begin{tabular}{|c|c|c|c|c|c|c|}
\hline Isolation number & Age (years) & Race & Sex & HbA1c (\%) & $\mathrm{BMI}$ & Cause of death \\
\hline Donor \#1 & 47 & C & $M$ & 4.7 & 31.7 & CVA \\
\hline Donor \#2 & 27 & $\mathrm{H}$ & M & 5.2 & 30.7 & $\mathrm{~T}$ \\
\hline Donor \#3 & 39 & C & M & 5 & 30 & ICB \\
\hline Donor \#4 & 17 & $\mathrm{H}$ & M & 5.2 & 39.4 & $\mathrm{HT}$ \\
\hline Donor \#5 & 38 & C & M & 5.2 & 26.3 & HT \\
\hline Donor \#6 & 34 & C & M & 4.8 & 33.1 & $\mathrm{HT}$ \\
\hline Donor \#7 & 27 & $\mathrm{H}$ & M & 5 & 24.7 & CVA \\
\hline Donor \#8 & 31 & $\mathrm{H}$ & M & 5.3 & 31.8 & HT \\
\hline Donor \#9 & 44 & AA & M & 5.2 & 20.3 & HT \\
\hline Mean \pm SEM & $33.8 \pm 3.1$ & NA & NA & $5.1 \pm 0.1$ & $29.8 \pm 1.8$ & NA \\
\hline
\end{tabular}

BMI body mass index, HbA1c hemoglobin A1c, C Caucasian, $H$ Hispanic, CVA cerebrovascular accident, $H T$ head trauma, $A A$ African-American, NA not applicable 
were collected and the IPTD-MSCs were cultured as described below.

Intra-pancreatic tissue-derived cell harvesting and culture Enzymatic digestion of the whole pancreata released intra-pancreatic tissue and stromal cells. These cells were found to be less dense than the islets and acinar clusters. Under the standard centrifugation condition $(182 \times g$ for $3 \mathrm{~min})$, which was prioritized for islets and acinar clusters, the stromal cells were located at the top layer of the conical tubes (Fig. 1). Until now, this top layer of tissue and cells has been routinely discarded.

To test our hypothesis that IPTD-MSCs can be separated from fractions of the pancreatic tissue, we modified our standard protocol, collected and pooled the upper layer found post-centrifugation, and passed the resultant through double layers of mesh filters (500 and $300 \mu \mathrm{m})$ to eliminate non-cellular components (Fig. 1). The filtered cells were then washed with CMRL1066 culture medium and centrifuged at $727 \times g / 8^{\circ} \mathrm{C}$ for $3 \mathrm{~min}$. The supernatant was aspirated, and the pellet was suspended in CMRL-1066 culture medium supplemented with 5\% Human Platelet Lysate (hPL, Compass Biomed, MA) followed by transferring to a $50-\mathrm{mL}$ conical tube. The suspended cells were centrifuged at $727 \times g / 8^{\circ} \mathrm{C}$ for $3 \mathrm{~min}$. The supernatant was aspirated, and the pellet was suspended in $40 \mathrm{~mL}$ of CMRL-1066 medium containing $5 \% \mathrm{hPL}$ followed by culturing in $\mathrm{T}$ 175 adherent flasks (ThermoFisher Scientific, Waltham, MA) for $24 \mathrm{~h}$ at $37^{\circ} \mathrm{C}$ in $5 \% \mathrm{CO}_{2}$ (Fig. 1). Twenty-four hours later, the medium was replaced with fresh CMRL1066 medium containing 5\% hPL. Additional media changes were performed every $48 \mathrm{~h}$ until cells reached 80-90\% confluence.

\section{Bone marrow-derived MSCs}

Bone marrow-derived human MSCs were obtained from healthy individuals as described [31, 32]. All subjects gave written informed consent in accordance with the
Declaration of Helsinki. The study protocol was approved by the Medical Ethics Board of Leiden University Medical Center (LUMC).

\section{Characterization of IPTD-MSCs Cell morphology}

To record the growth and morphology of cultured cells, multiple pictures at different magnifications and time points were obtained using a ckx31 Olympus microscope.

\section{Flow cytometry}

After reaching 80-90\% confluence, cells were dissociated with TrypLE (ThermoFisher, San Diego), washed with DPBS (Corning, Tewksbury, MA) twice, and incubated with antibodies specific for cell-surface molecules, including CD90, CD105, CD73, CD9, CD45, CD34, CD14, and HLA-DR (BioLegends, San Diego, CA), for $20 \mathrm{~min}$ at room temperature. In parallel, aliquots of cells were incubated with matched isotype control antibodies from the same supplier. After antibody incubation, cells were washed twice with DPBS and suspended in DPBS for flow cytometry analysis using a Sony SA3800 Spectral Analyzer (Sony Biotechnology, San Jose, CA). Data analysis was performed using Flowjo software (Tree Star, Ashland, OR). To verify the results, human bone marrow-derived MSCs were cultured in the same medium used for IPTD-MSCs, passaged, and expanded in the same procedures for subsequent analysis.

\section{Immunofluorescent staining for IPTD-MSCs and pancreatic tissue}

Cells were cultured to $70-80 \%$ confluence and dissociated into a single-cell suspension using TrypLE as described [33]. Cells and pancreatic tissue were then fixed in $10 \%$ cold formalin, prepared in a paraffin block, and sectioned. Antigen retrieval was performed using a citric acid-based antigen unmasking solution (Vector, pH 6.0). Sections were treated with protein block (Biogenex, Fremont, CA) to reduce background signal, followed by

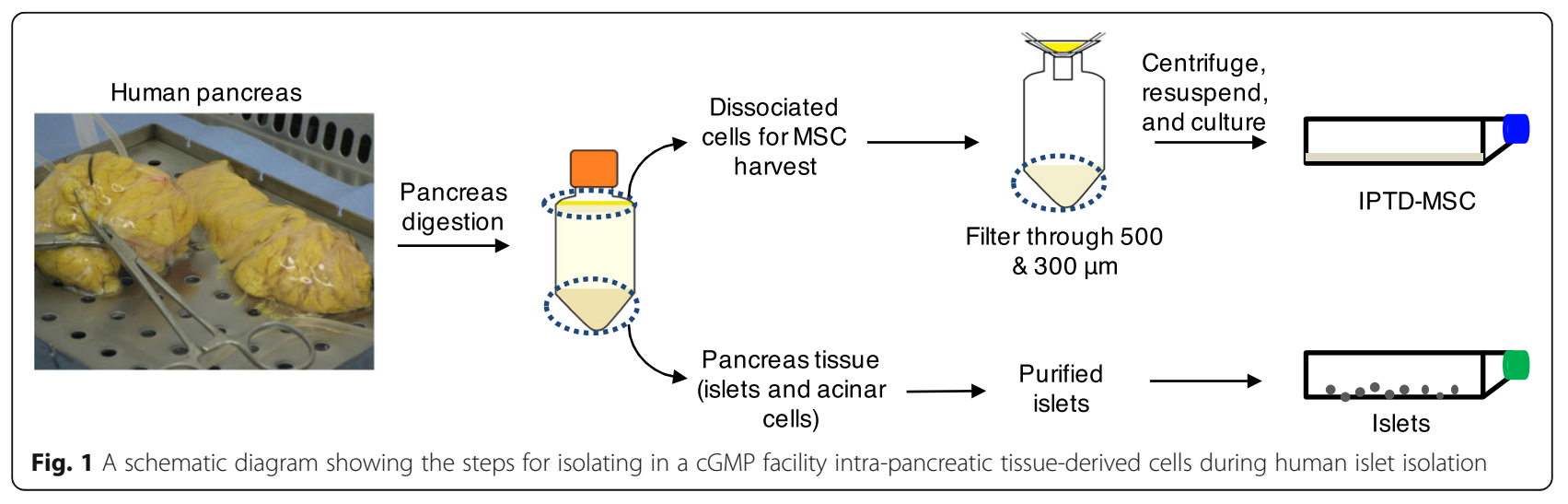


incubation with mouse anti-CD105 antibody (ready to use; Biogenex) and ALEXA 488-conjugated goat antimouse IgG antibody (1:200 dilution; ThermoFisher). Guinea pig anti-insulin (ThermoFisher) and ALEXA 647-conjugated goat anti-Guinea pig IgG antibodies (1: 200 dilution; ThermoFisher) were used for pancreatic tissue staining only. Fluoroshield ${ }^{\mathrm{m}}$ containing DAPI (Sigma Aldrich St. Louis, MO) was used to stain nuclei. Image acquisition was done using an Observer Z1 microscope (Carl Zeiss), with the objective lens set at $20 \times$. Image processing was done using the Zen 2.0 software.

\section{Multilineage differentiation of IPTD-MSCs}

IPTD-MSCs at the second passage were cultured in T75 tissue culture flasks until $\sim 85 \%$ confluence. For adipogenic differentiation, IPTD-MSCs were seeded into 6well plates and cultured in MesenCult ${ }^{\mathrm{tm}}$ Adipogenic Differentiation Kit (STEMCELL Technologies, Vancouver, Canada; Cat\# 05412) for 21 days with media changed every 3 days. The presence of lipid droplets in cells was determined by staining with Oil Red O (Sigma, cat\# O0625) 21 days after culture. For chondrogenic differentiation, IPTD-MSCs were cultured in two $15-\mathrm{mL}$ conical tubes in MesenCult ${ }^{\mathrm{m}}-\mathrm{ACF}$ Chondrogenic Differentiation medium (STEMCELL Technologies, Cat\# 05455) for 24 days with media changed every 3 days. After culture, Alcian Blue (Sigma, cat\#66011) was used to stain for both fresh cells and the cells fixed in paraffin sections. For osteogenic differentiation, cells were cultured in a T-75 tissue culture flask for 22 days with media changed every 3 days. The osteogenic differentiation medium consisted of CMRL-1066 containing 10 $\mathrm{mM} \beta$-glycerophosphate (Sigma, Cat\# G-6251), $50 \mu \mathrm{g} /$ $\mathrm{mL}$ L-ascorbate acid 2-phosphate (Cayman, Item \# 16457), $1 \mu \mathrm{M}$ of dexamethasone (Fresenius Kabi, Cat\# 401780G), and 3\% hPL. Differentiated cells were fixed in paraffin section and stained with von Kossa for calcium deposition. Undifferentiated IPTD-MSCs were cultured in standard culture medium lacking differentiation factors and stained with Oil Red O, Alcian Blue, or von Kossa.

\section{In vitro expansion of IPTD-MSCs}

T-175 flasks of $\sim 80 \%$ confluent passage-3 cells were washed twice with DPBS, and $5 \mathrm{ml}$ of TrypLE enzyme was added to each flask. The cells were incubated at $37^{\circ} \mathrm{C}$ for $5-10 \mathrm{~min}$ to dissociate adherent cells, and 10 $\mathrm{ml}$ of CMRL-1066 medium was added to terminate enzyme digestion. Cells were collected in $15-\mathrm{ml}$ tubes for centrifugation at $528 \times g$ for $3 \mathrm{~min}$. The cell pellet was suspended in $5 \mathrm{ml} \mathrm{CMRL-1066}$ with 5\% hPL and vortexed. A sample of cells was mixed in a 1:1 ratio with $0.4 \%$ trypan blue (ThermoFisher), from which $20 \mu \mathrm{L}$ was placed on a counting slide (Cellometer SD100, Nexcelom Bioscience, San Diego, CA) and counted using a Cellometer Auto T4 (Nexcelom Bioscience, San Diego, CA). To further characterize the growth capabilities of these cells, we performed subcultures by placing $5 \times 10^{4}$ cells in T-25 flasks for $72 \mathrm{~h}$ at $37^{\circ} \mathrm{C}$ and $5 \% \mathrm{CO}_{2}$. Some cells were grown in CMRL-1066 culture medium alone and others in CMRL-1066 culture medium supplemented with $5 \%$ hPL. Culture medium was replaced once during this period. At the end of the culture, cells were dissociated and counted as above. This process was then repeated. After each passage, the cell count was multiplied by the dilution factor to calculate the total number of cells per passage.

\section{Cryopreservation of IPTD-MSCs}

Isolated IPTD-MSCs (at passage 3) were cultured to $80 \%$ confluence, dissociated into single cells with TrypLE, collected, and counted. Aliquots of $1 \times 10^{6}$ cells were divided into cryopreservation tubes, suspended in 10\% DMSO in CMRL-1066 medium, and stored at $80^{\circ} \mathrm{C}$ in a Mr. Frosty Freezing apparatus containing $100 \%$ isopropyl alcohol (ThermoFisher). Using this method, IPTD-MSCs were stored for 9 months. The cells were then thawed rapidly in a $37^{\circ} \mathrm{C}$ water bath, washed with DPBS, and cultured in T-75 tissue culture flasks using CMRL media with 5\% hPL. After $48 \mathrm{~h}$, the cells were noted to be $\sim 80 \%$ confluent and were subjected to subsequent analyses. Viability was assessed with trypan blue.

\section{In vitro treatment of IPTD-MSCs with TNF- $a$ and DMOG} Recombinant human TNF- $\alpha$ protein (R\&D Systems, Minneapolis, MN) was reconstituted in research-grade water (Hospira, Lake Forest, IL) to a concentration of $100 \mathrm{ng} / \mathrm{mL}$, aliquoted, and stored at $-20^{\circ} \mathrm{C}$. Dimethyloxallyl glycine (DMOG; Cayman Chemicals, Ann Arbor, MI) was dissolved in water to yield a stock solution of $57.1 \mathrm{mM}$, aliquoted $(100 \mu \mathrm{L})$, and stored at $-80^{\circ} \mathrm{C}$. IPTD-MSCs were incubated in T-25 flasks in $5 \mathrm{ml}$ of CMRL-1066 medium supplemented with 5\% hPL until $\sim 50 \%$ confluent. Cells were cultured for $24 \mathrm{~h}$ in CMRL 1066 medium, or medium containing $10 \mathrm{ng} / \mathrm{ml}$ TNF- $\alpha$, $1 \mathrm{mM}$ DMOG or $1 \mathrm{mM}$ DMOG and $10 \mathrm{ng} / \mathrm{ml}$ TNF- $\alpha$. Following treatment, cells were collected in $1.7-\mathrm{ml}$ Eppendorf tubes and stored in RLT buffer (Qiagen, Germantown, MD) at $-80^{\circ} \mathrm{C}$ for future preparation of cDNA.

\section{Quantitative real-time PCR}

The TaqMan Gene Expression Assay system (ThermoFisher Scientific) was used to quantify $\beta$-ACTIN, TSG-6, NRF2, and VEGF mRNA levels. Total RNA was extracted using a Qiagen Mini Kit (Cat. No. 51306) and 
converted into cDNA. Real-time quantitative PCR was run in duplicate on a ViiA ${ }^{\text {tw }} 7$ Real-Time PCR System with a 384-well block (ThermoFisher Scientific). Thermal cycles were programmed for $20 \mathrm{~s}$ at $95^{\circ} \mathrm{C}$ for the initial denaturation, followed by 45 cycles of $120 \mathrm{~s}$ at $95^{\circ} \mathrm{C}$ for denaturation, $30 \mathrm{~s}$ at $60^{\circ} \mathrm{C}$ for annealing, $60 \mathrm{~s}$ at $72{ }^{\circ} \mathrm{C}$ for extension, and a final extension at $72{ }^{\circ} \mathrm{C}$ for $10 \mathrm{~min}$. All PCR runs were performed with negative (water) and positive controls. $\beta$-ACTIN was used as an internal control to quantify relative gene expression.

\section{Cytokine assay}

Supernatants from cells cultured for $24 \mathrm{~h}$ under various conditions (medium alone, or medium plus DMOG, TNF- $\alpha$, or DMOG + TNF- $\alpha$ ) were collected, and cytokine analysis performed using a Luminex assay kit (Bio-Rad, Hercules, CA) according to the manufacturer's protocol. The following growth factors/cytokines were measured: VEGF, IL-6, IL-8, MMP-9, MCP-1, MMP-2, IL-4, IL-10, and IL-1 $\beta$. Samples were measured in duplicate.

\section{In vitro angiogenesis assay}

Angiogenic capacity was assessed by quantifying endothelial tube formation [34]. Human umbilical vein endothelial cells (HUVECs) (Cell Applications Inc., San Diego, CA; Cat\# 200p-05n) between passages 2 and 6 were cultured in a standard medium. Cells $\left(1 \times 10^{5}\right.$ cells/ well) were plated in 24-well plates (Fisher, Cat \# 930186) coated with Matrigel (Corning, Cat\# 356234), and incubated for $30 \mathrm{~min}$ to allow cell attachment. Supernatants $(150 \mu \mathrm{L} /$ well $)$ from control and stimulated IPTD-MSCs (DMOG, TNF- $\alpha$, or DMOG + TNF- $\alpha$ ) were added to obtain a total volume of $300 \mu \mathrm{L}$ per well. Plates were then incubated at $37^{\circ} \mathrm{C}, 5 \% \mathrm{CO}_{2}$ for $24 \mathrm{~h}$. At 4 and $24 \mathrm{~h}$, the wells were visualized using a Leica microscope and representative photographic images were obtained. Total endothelial tube number and tube length were determined using ImageJ software (NIH, Bethesda, MD).

\section{Statistical analysis}

Data was analyzed with GraphPad Prism software (GraphPad Software 8.0, La Jolla, CA). ANOVA one-way analysis of variance was used to compare multiple experimental groups followed by the Tukey multiple comparisons test to compare the mean values between any two groups. All the values were expressed as mean \pm standard error of mean (SEM). For all the tests, $p<0.05$ was considered significant.

\section{Results}

\section{A chemically defined medium supports the growth IPTD- MSCs}

To develop a GMP-compatible culture medium, we tested whether hPL could support the growth of IPTDMSCs in the absence of fetal bovine serum. Under phase-contrast microscopic evaluation, IPTD-MSCs displayed elongated and spindle shapes (Fig. 2a), a morphology consistent with the classic MSCs derived from other tissues [35]. Next, we dissociated and replated IPTD-MSCs multiple times and found that the spindle shape morphology was preserved throughout numerous passages (Fig. 2b). IPTD-MSCs were cryopreserved for 9 months, thawed, and cultured, and again the cell morphology remained stable (Fig. 2c).

\section{$\mathrm{hPL}$ is required for the growth of IPTD-MSCs}

We tested whether hPL is essential for the growth of IPTD-MSCs by removing it from the culture medium and passaging cells for three generations. IPTD-MSCs grown in hPL-repleted medium expanded an average of 10.8fold, while those cultured in medium lacking hPL showed minimal to no expansion (Fig. 3), suggesting that hPL is required for the expansion of IPTD-MSCs in vitro.

\section{IPTD-MSCs display classic MSC cell-surface markers}

To test whether IPTD-MSCs express known markers found on MSCs isolated from bone marrow and other

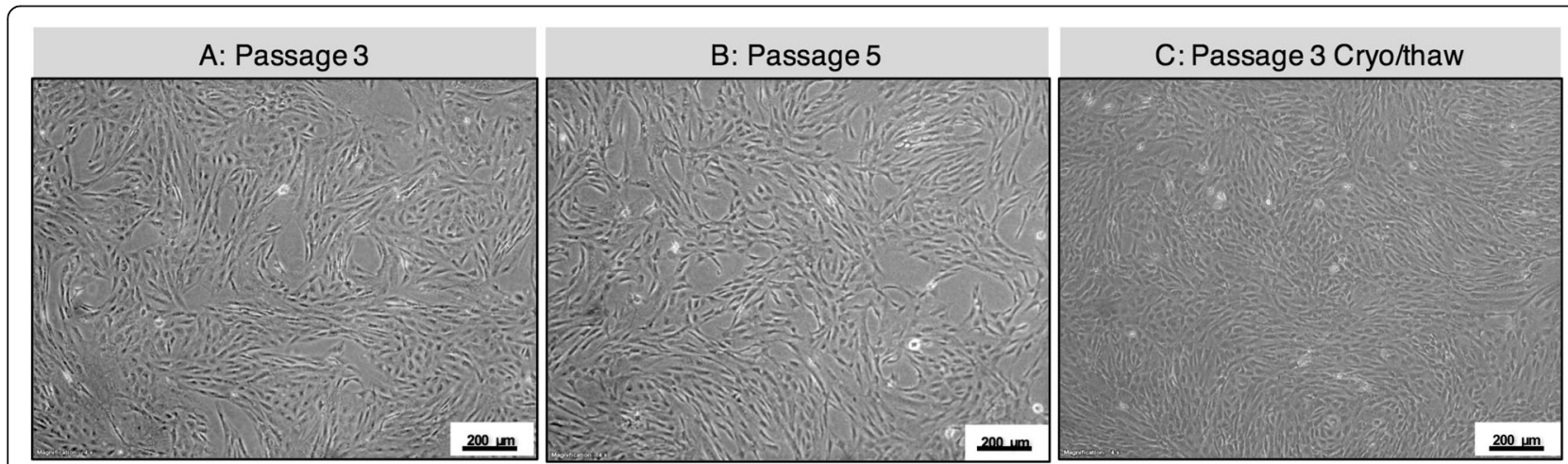

Fig. 2 IPTD cells resemble MSCs in culture and can be cryopreserved Phase contrast microscopy of IPTD-MSCs cells cultured in CMRL-1066 medium supplemented with 5\% hPL. a Passage 3 cell culture on day 3; b passage 5 cell culture on day 3; c passage 3 cells after 9 months of cryopreservation, thawing, and culture on day 3. Representative images are presented. Scale bar, $200 \mu \mathrm{m}$ 
A

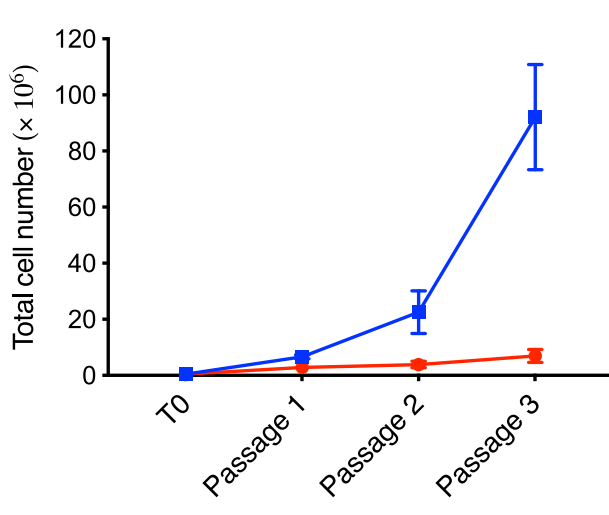

B

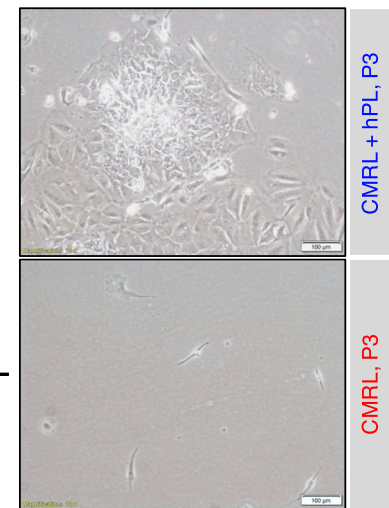

Fig. 3 The growth of IPTD-MSCs is enhanced by a culture medium supplemented with hPL. a Total cell numbers during expansion under the designated culture conditions. hPL was essential for the expansion of cells in vitro. The results shown were from three different tissue donors; $\mathbf{b}$ A representative photomicrograph of passage 3 cells cultured in CMRL-1066 culture medium with (green) and without (red) 5\% hPL. Scale bar, $100 \mu \mathrm{m}$

organs [36], we performed flow cytometry analysis. We first confirmed cell-surface marker expression using bone marrow-derived MSCs. As expected, the majority of bone marrow-derived MSCs expressed CD90, CD105, CD73, and CD9 and showed minimal to no expression of CD45 (pan-leukocytes), CD34 (hematopoietic cells), CD14 (macrophages), and HLA-DR (antigen-presenting cells) (Fig. 4a).

IPTD-MSCs were passaged 3 times, dissociated into a single-cell suspension and stained with the above mentioned antibodies. Compared to isotype-control staining, the vast majority of IPTD-MSCs stained positive for CD90 (99.2 $\pm 0.3 \%)$, CD105 (99.8 $\pm 0.2 \%)$, CD73 (99.6 \pm $0.3 \%$ ), and CD9 $(86.8 \pm 2.6 \%)$ (Fig. 4a). Minimal expression of CD45 $(0.3 \pm 0.2 \%)$, CD34 $(0.3 \pm 0.0 \%), \mathrm{CD} 14$ $(1.5 \pm 0.8 \%)$, and HLA-DR was found (Fig. 4a). Expression of CD105 on the cell surface of IPTD-MSCs at passages 3 and 5 was further visualized using immunofluorescent staining (Fig. 4b). Taken together, IPTDMSCs expressed classic positive and lacked negative markers for MSCs, suggesting that they reside within the MSC family of cells.

\section{$\mathrm{CD} 105^{+}$cells localize in the pancreas near insulin- expressing cells}

To rule out the possibility that the ex vivo IPTD-MSC growth and expansion was due to in vitro selection or artifact, we examined whether $\mathrm{CD}_{105^{+}}$cells were present in the endogenous pancreas. Pancreatic tissue sections were co-stained with CD105 and insulin. $\mathrm{CD} 105^{+}$cells were detected in the pancreatic tissue and were located adjacent to the insulin-expressing islets (Fig. 5). This result confirms the existence of $\mathrm{CD} 105^{+}$ cells in the adult human pancreas.
IPTD-MSCs have potential to differentiate into multiple cell lineages in vitro

A typical feature of MSCs is the ability to assume lineage-specific cell phenotypes after exposure to certain growth factors. IPTD-MSCs were exposed to adipogenic, chondrogenic, and osteogenic growth conditions. Under these differentiation conditions, IPTD-MSCs were found to give rise to the appropriate lineage-associated phenotypes, including cells positively stained for Oil Red $\mathrm{O}$ (adipocytes), Alcian Blue (chondrocytes), or von Kossa (osteoblasts) (Fig. 6). In contrast, undifferentiated IPTDMSCs showed no lineage-specific staining.

\section{TNF- $a$ and DMOG upregulate immune-regulatory and angiogenic genes in IPTD-MSCs}

Next, we tested whether IPTD-MSCs were amenable to in vitro conditioning. IPTD-MSCs were stimulated with TNF- $\alpha$ and/or DMOG, and the expression of known immune-modulating and angiogenic genes was determined. Consistent to previous findings [27], TSG-6 gene expression levels were significantly increased in cells treated with $10 \mathrm{ng} / \mathrm{ml}$ TNF- $\alpha(p<0.01)$ but not DMOG alone (Fig. 7a), compared to control. Addition of DMOG to TNF- $\alpha$ further increased the expression of TSG-6 $(p<0.0001)$ (Fig. 7a). NRF2 and VEGF expression were significantly increased when cells were treated with DMOG $(p<0.05$ and $p<0.001$ respectively, Fig. 7b, c) but not TNF- $\alpha$ alone, compared to control. Addition of DMOG to TNF- $\alpha$ further enhanced the expression of NRF2 and VEGF $(p<0.0001$, Fig. $7 \mathrm{~b}, \mathrm{c})$. These results suggest that, while TNF- $\alpha$ and DMOG display divergent effects, the combination of the two best enhances in IPTD-MSC genes that are known to modulate immune responses and angiogenesis. 


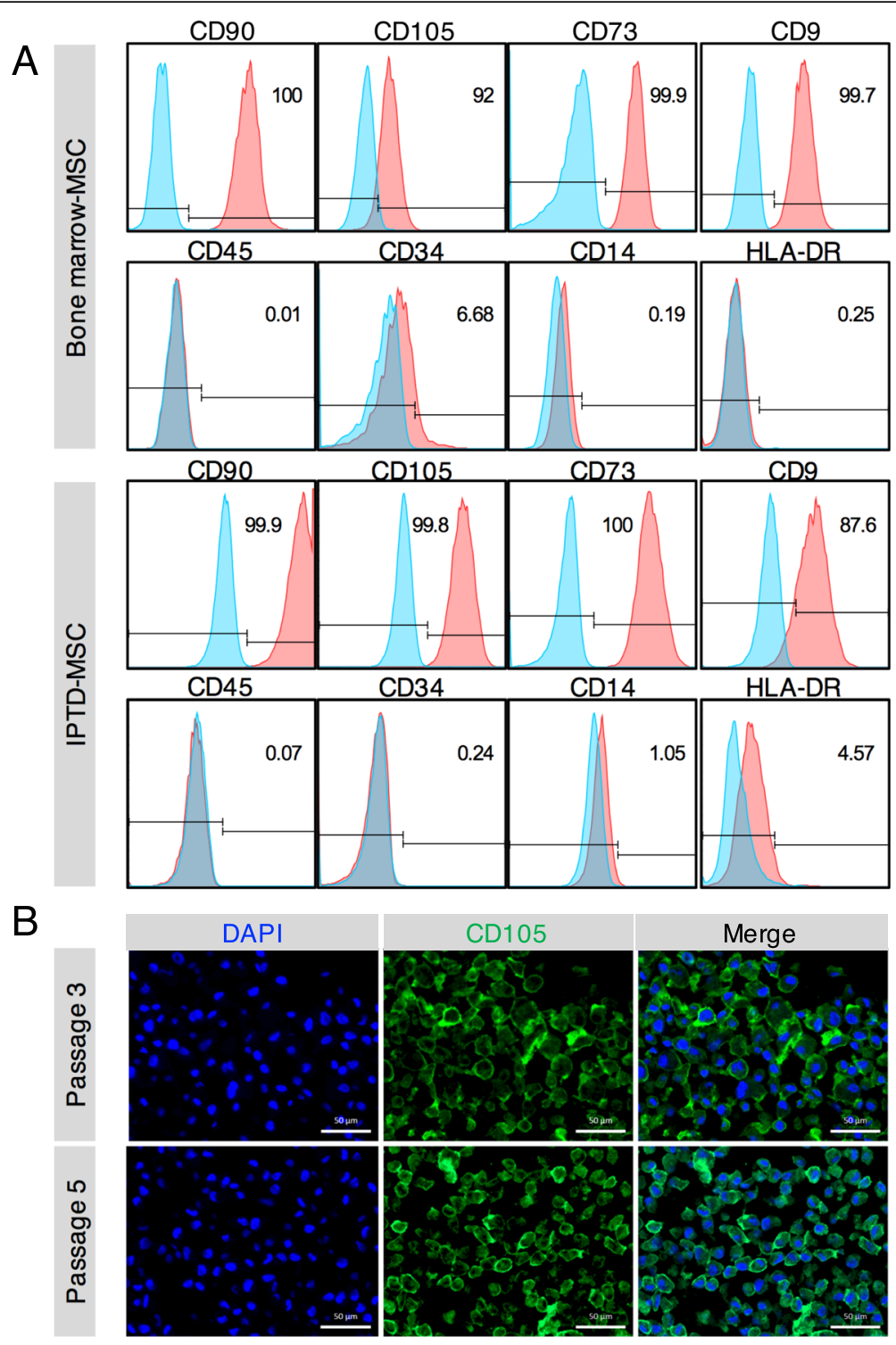

Fig. 4 IPTD-MSCs display a cell-surface protein profile consistent with classic MSCs. a Flow cytometry analysis of cell-surface protein expression of bone marrow-derived MSCS and IPTD-MSCS. Data are representative of four pancreas donors. $\mathbf{b}$ Immunofluorescent staining for CD105 protein expression (green) in paraffin sections of IPTD-MSCs (passages 3 and 5) grown in the presence of $\mathrm{hPL}$. Scale bar $=50 \mu \mathrm{m}$. DAPI stains nuclei

\section{TNF- $a$ and DMOG alter growth factors and cytokines} released by IPTD-MSCs

To further characterize IPTD-MSCs, we examined proteins released from these cells. IPTD-MSCs were cultured for 24 $h$ in the presence of exogenous TNF- $\alpha$, DMOG, or both, and the resulting culture media were examined by Luminex assay. Compared to control, stimulation of IPTD-MSCs with DMOG alone enhanced the secretion of VEGF, IL-6, IL-8, and IL-4 (Fig. 8; comparing the 1st to the 2nd bars). Stimulation of IPTD-MSCs with the combination of DMOG plus TNF- $\alpha$ enhanced the secretion of VEGF, IL-6, and IL-4 (Fig. 8; comparing the 1st to the 4th bars), while the stimulation of IPTD-MSCs with TNF- $\alpha$ alone did not have an effect on any of the cytokines examined compared to controls. The addition of TNF- $\alpha$ to DMOG enhanced the secretion of IL-6 and IL-4 (Fig. 8; comparing the 2nd to the 4th bars). Levels of MCP-1 were reduced in the conditioned media of IPTD-MSCs treated with DMOG or DMOG plus TNF- $\alpha$, but not with TNF- $\alpha$ alone. Levels of MMP-9, MMP-2, and IL-10 were not changed in response to various conditioning while $\mathrm{L}-1 \beta$ was undetectable.

Conditioned medium from IPTD-MSCs stimulated with DMOG promotes angiogenic activity of endothelial cells Endothelial cell tube formation is an acknowledged angiogenic metric indicative of cell migration, adhesion, 

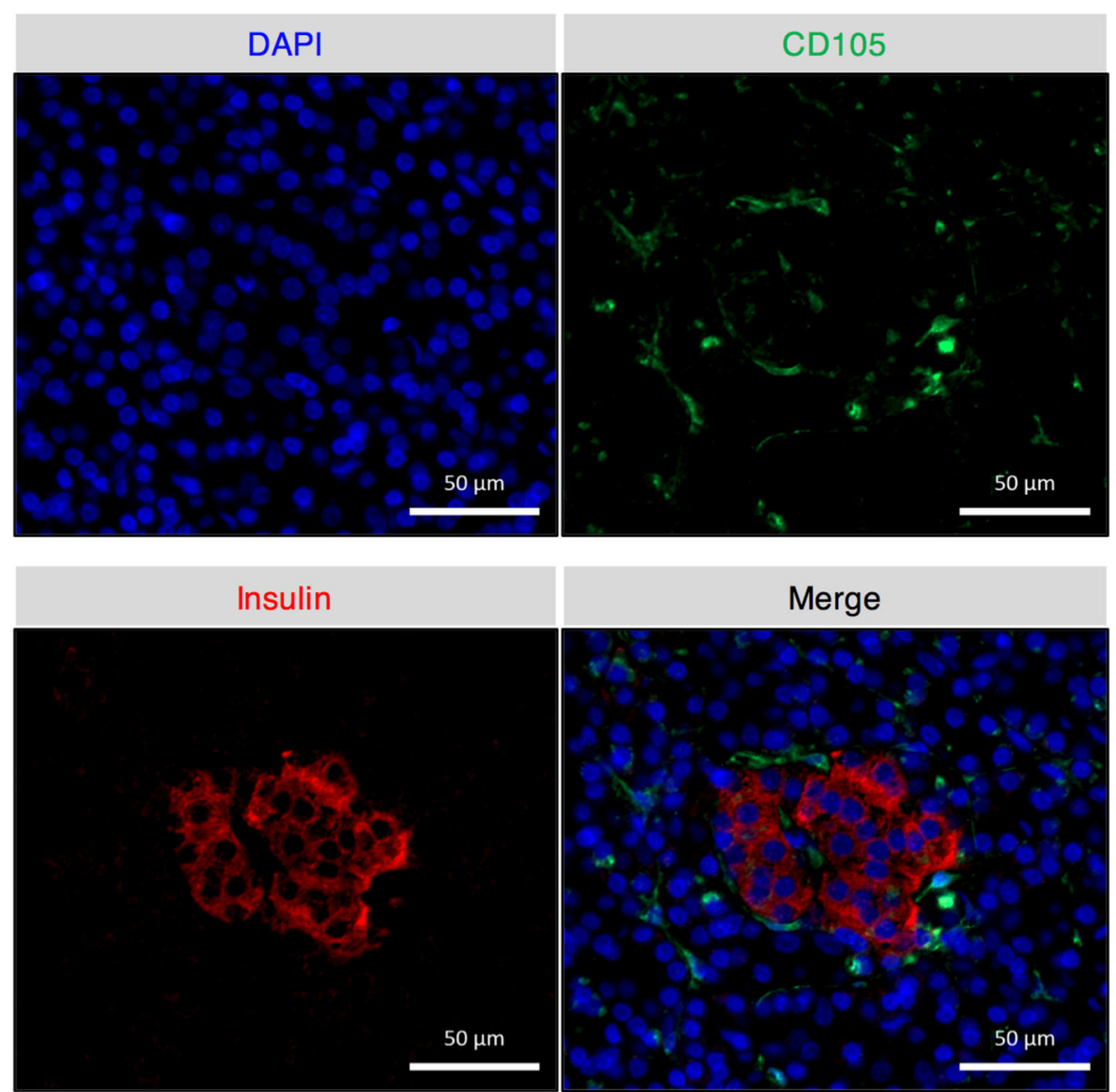

Fig. 5 Cells expressing CD105 are found in non-digested pancreatic tissue. Double immunofluorescent staining for CD105 (green) and insulin (red) revealed that CD105-positive cells are present in the pancreatic tissue and located adjacent to the insulin-expressing islets. Photomicrographs were obtained using a Z1 microscope (Carl Zeiss) at flourescence wavelengths of $488 \mathrm{~nm}$ (CD 105) and $647 \mathrm{~nm}$ (insulin). Images are representative of 3 separate experiments. Scale bars, $50 \mu \mathrm{m}$

and re-organization. To test this, HUVECs were exposed to conditioned media from IPTD-MSCs stimulated with TNF- $\alpha$, DMOG, or both. Four hours post-plating, HUVECs treated with various IPTD-MSC conditioned media displayed similar morphology without significant difference in tube number or length, regardless of the source of the media. By $24 \mathrm{~h}$, endothelial tube formation was apparent (Fig. 9a). HUVECs incubated with media from IPTD-MSCs treated with DMOG $(21.0 \pm 2.0, p<$ $0.01)$ or DMOG + TNF- $\alpha(26.0 \pm 2.0, \mathrm{p}<0.01)$ displayed increased numbers of cell tubes, compared to control $(3.5 \pm 0.5)$ (Fig. 9b). Similarly, tube length was significantly higher in HUVECs exposed to IPTD-MSC conditioned media stimulated with DMOG $(28.6 \pm 9.9 \mathrm{~mm}$, $p<0.05)$ or DMOG + TNF- $\alpha(43.6 \pm 0.8 \mathrm{~mm}, \mathrm{p}<0.05)$, compared to control $(10.3 \pm 1.0 \mathrm{~mm})$ (Fig. $9 \mathrm{~b})$. TNF- $\alpha$ by itself had no effect on tube number or length, and TNF$\alpha$ did not enhance the effects of DMOG (Fig. 9b; comparing the 2nd and the 4th bars), suggesting that DMOG is the sole stimulant to enhance IPTD-MSC-mediated angiogenesis in vitro.

\section{Discussion}

We identified a MSC population that resides within pancreatic tissues, which can be separated during islet isolation. We named these cells intra-pancreatic tissuederived (IPTD)-MSCs, in agreement with the recent call for nomenclature of MSCs in relation to their tissue of origin [37-39]. In culture, IPTD-MSCs displayed features similar to classic bone marrow- or umbilical cord blood-derived MSCs, including adherence to culturegrade plastic surfaces, spindle-shaped morphology, expression of appropriate surface markers (positive for CD90, CD105, and CD73, and negative for CD45, CD34, CD14 and HLA-DR), and capacity for proliferation and multilineage differentiation. Furthermore, when IPTDMSCs were treated with a combination of TNF- $\alpha$ and DMOG, we observed (1) increased mRNA levels of 


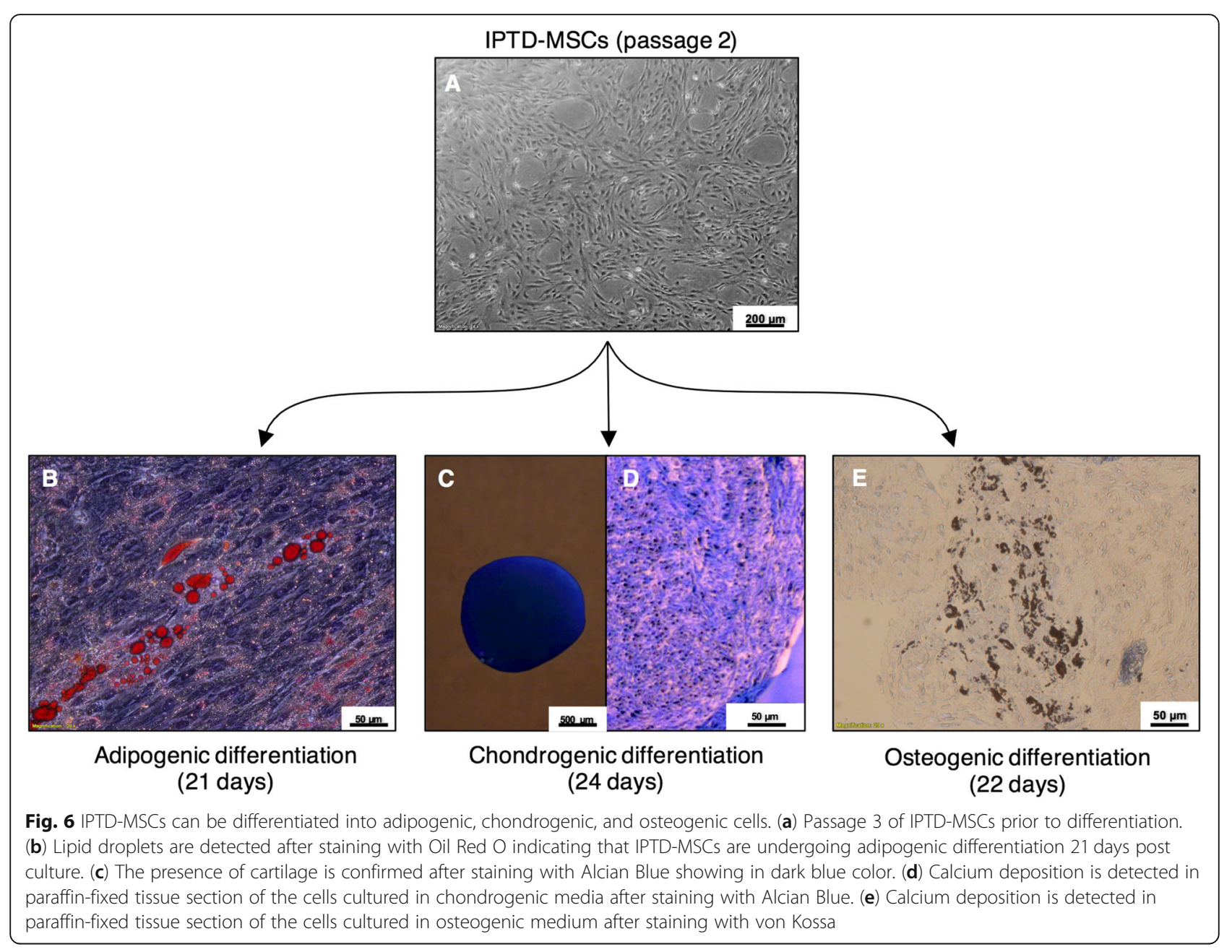

TSG-6, NRF2, and VEGF; (2) increased secretion from IPTD-MSCs of VEGF, IL-6, IL-8, and IL-4; (3) decreased secretion of MCP-1; and (4) enhanced endothelial cell tube formation. Together, these results suggest IPTDMSCs conditioned by TNF- $\alpha$ and DMOG have antiinflammatory and pro-angiogenic potential.

The cell population, isolation, and culture method of IPTD-MSCs we described herein have both differences and similarities over other previously published MSCs [40]. In this study, cells were isolated from intrapancreatic tissue as a part of islet isolation procedure from a single donor. IPTD-MSCs were harvested from an otherwise discarded component after routine pancreatic digestion and islet isolation. The GMP-compatible protocol used for culturing these cells led to the production of large numbers of highly purified MSCs. We deliberately selected CMRL-1066 as the base medium to propagate IPTD-MSCs because CMRL-1066 is routinely used to culture islets for transplantation, thus reducing the burden for future clinical translation. Additionally, we eliminated animal products in culture media by using $\mathrm{hPL}$, which will lower the risks of infection, allergic reactions, and product variability. Similar to MSCs derived from other tissue sources, IPTD-MSCs are capable of differentiation into adipocyte, chondrocyte, and osteoblast lineages, demonstrating the multi-lineage potential of IPTD-MSCs.

This study demonstrates an approach that allows for harvesting islets and IPTD-MSCs simultaneously from a single donor under GMP conditions, facilitating direct clinical application. Harvesting IPTD-MSCs during human islet isolation makes the quality evaluation of isolated cells rapid and reliable and suggests opportunities for immediate clinical applications. Previously, autologous bone marrow-derived MSCs have been used simultaneously in living-related kidney transplant recipients [41]. Moreover, we expanded bone marrow-derived MSCs in the same medium of CMRL-1066 supplemented with hPL and found that these MSCs were similar in phenotype and characteristics compared to IPTD-MSCs, suggesting that our medium could be used to isolate MSCs from other tissue sources. IPTD-MSC culture medium used in this study is xenoprotein-free and cGMP-compatible. The isolated IPTD-MSCs were 


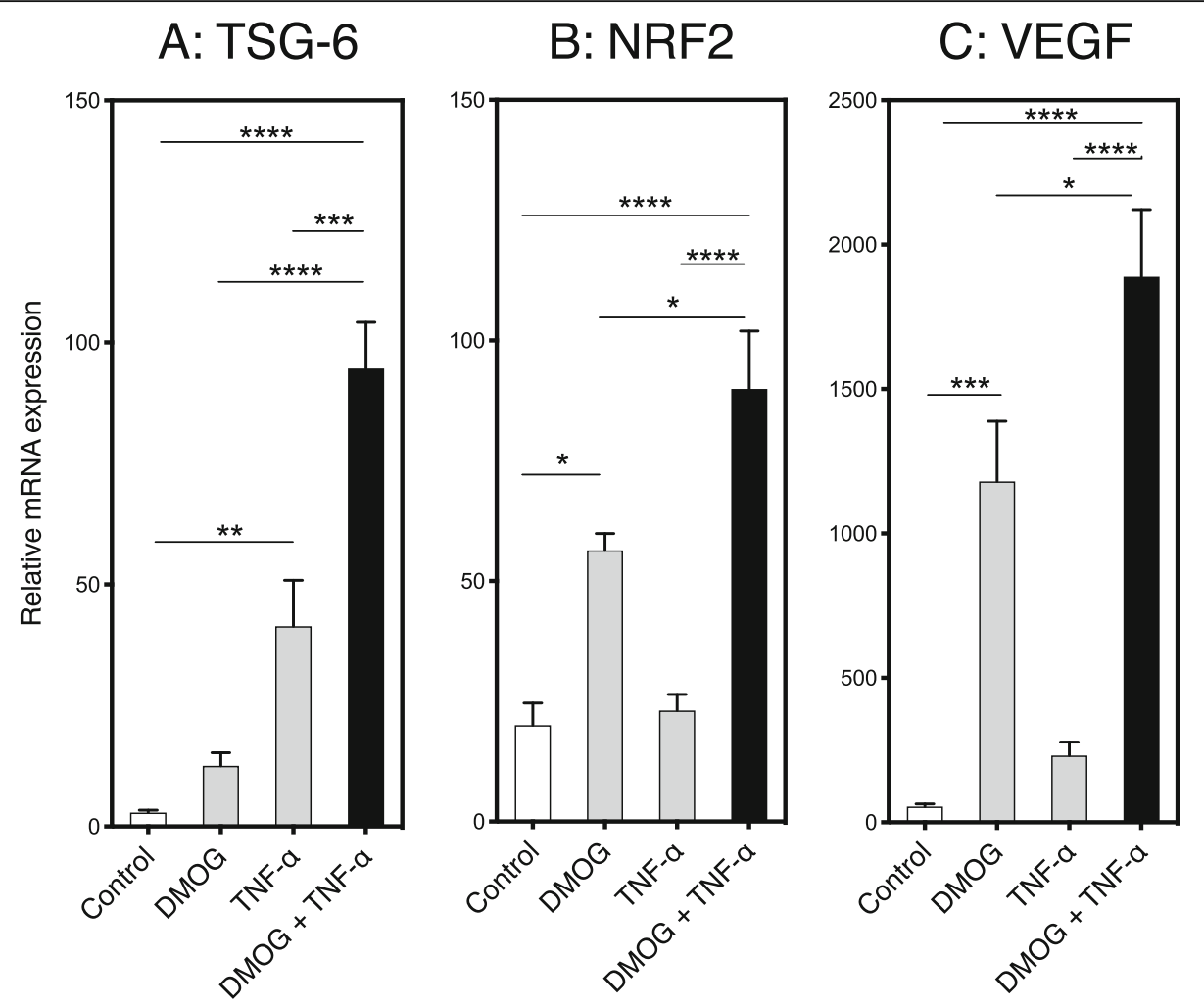

Fig. 7 IPTD-MSCs treated with TNF-a and DMOG display increased mRNA levels of anti-inflammatory and pro-angiogenic genes. a TSG-6, b NRF2, and $\mathbf{c}$ VEGF mRNA levels from IPTD-MSCs treated with TNF-a $(10 \mathrm{ng} / \mathrm{mL})$ and/or DMOG $(1 \mathrm{mM})$. Three independent donors were tested. The data are expressed as mean \pm SEM. ${ }^{*} p<0.05 ;{ }^{* *} p<0.01 ;{ }^{* * *} p<0.001 ;{ }^{* * *} p<0.0001$

expandable and can be produced in large scale using this culture medium. Conventionally, fetal bovine serum is supplemented in selected culture media to promote the growth of MSCs from different tissue sources [42]. However, the use of non-human serum to culture cells carries the potential of transmitting infectious agents [43], immunizing effects [44], and lot-to-lot variability. In this regard, human platelet lysate has been used to replace fetal bovine serum for clinical-scale MSC expansion [45]. In these studies, hPL was supplemented in minimal essential medium (MEM) to culture MSCs. In the current study, we used hPL to supplement the CMRL-1066 that has been optimized for human islets culture, and the culture system employed herein allows for optimum survival of IPTD-MSCs. This is important since a single medium system can be used for both cell sources to facilitate co-transplantation of islets and IPTD-MSCs in future studies.

This study also highlights the benefit of harvesting multiple cell types from tissue fractions of a single donor organ as part of the islet isolation procedure. It is conceivable that immunophenotypic characterization and identification of additional novel cell types residing within this tissue fraction would be valuable to study pancreatic pathophysiology arising from various diseases.
MSCs are known to reduce inflammation and enhance healing, and these functions can be further manipulated ex vivo to enhance capacities for cell therapies. Compared to control, we found that IPTD-MSCs exposed to a combination of TNF- $\alpha$ and DMOG, compared to single reagents, exerted a better overall outcome. Except for TSG-6 expression, no other molecules, including the secreted factors examined in this study, were affected by TNF- $\alpha$ treatment alone. In contrast, DMOG alone was able to induce $N R F 2, V E G F$ expression, as well as the secretion of VEGF, IL-6, IL-8, and IL-4. These results demonstrate a dominant effect of DMOG over TNF- $\alpha$. However, TNF- $\alpha$ was able to augment the effects brought by DMOG in increasing the expression of TSG6, NRF2, and VEGF and enhancing secretion from IPTD-MSCs of IL-6, IL-8, and IL-4. Regardless, the combination of TNF- $\alpha$ and DMOG appeared to be optimal for the examined outcomes, including the expression of TSG-6, NRF2, and VEGF; secretion of VEGF, IL-6, IL-8, and IL-4; and endothelial tube formation. To the best of our knowledge, this is the first study to show a beneficial effect on MSCs by conditioning with the combination of TNF- $\alpha$ and DMOG.

IL-4 levels were significantly increased by the combination of DMOG and TNF- $\alpha$ as compared to the control 


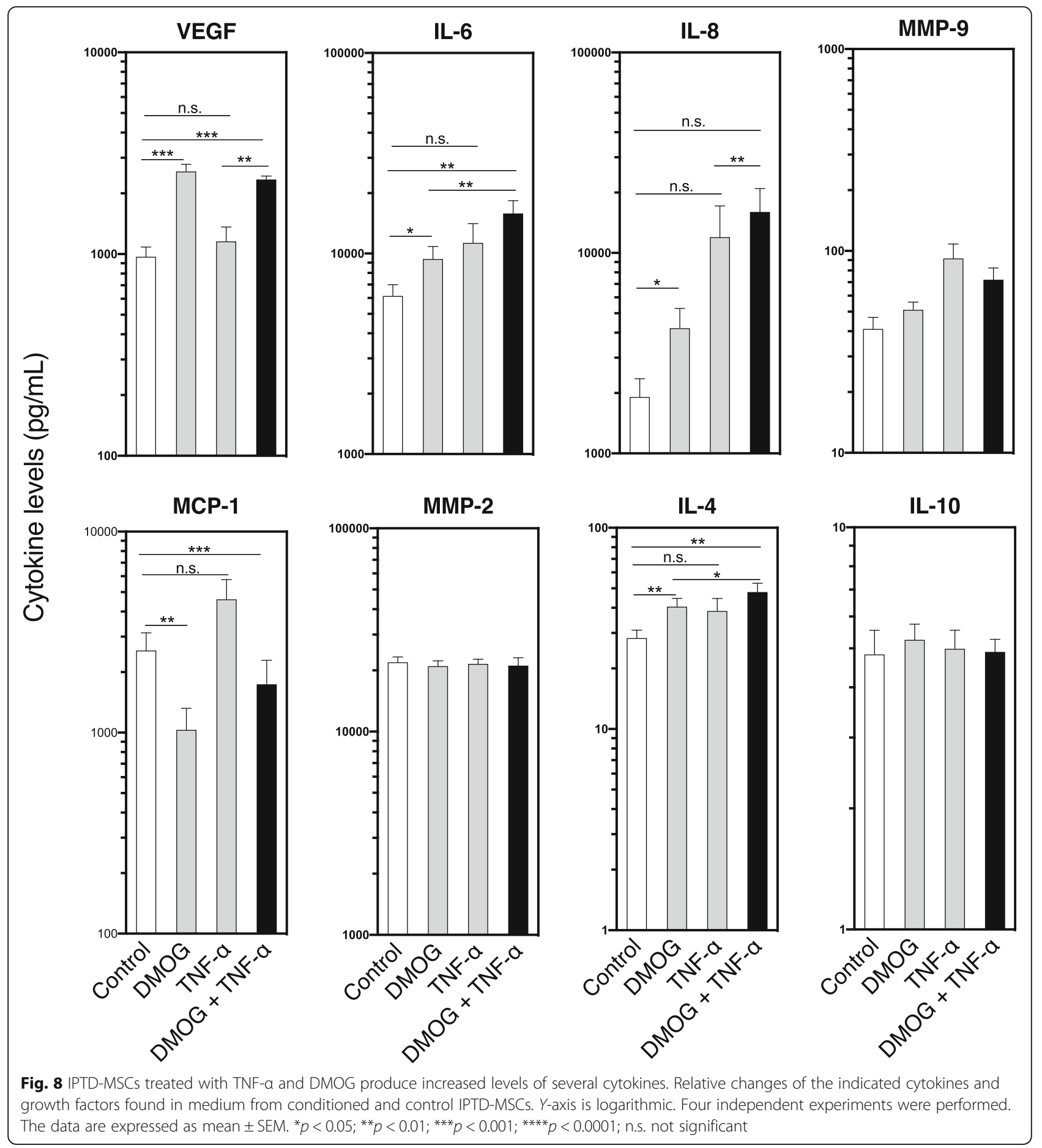

or DMOG alone, whereas IL-10 production was unchanged. This is in line with previous reports demonstrating that MSCs do not secrete IL-10, but stimulate other immune cells to secrete this cytokine [46]. MCP-1 (monocyte chemoattractant protein-1) is often increased upon treatment with inflammatory cytokines. We found that treatment of IPTD-MSCs with DMOG and TNF- $\alpha$ led to a reduction of MCP-1. Taken together, our results show the production of anti-inflammatory molecules in IPTD-MSCs. It remains to be determined if these human cells will provide protection in inflammatory settings.

VEGF, IL-6, IL-8, and MMP-9 are known proangiogenic factors [47-51], which may be responsible 


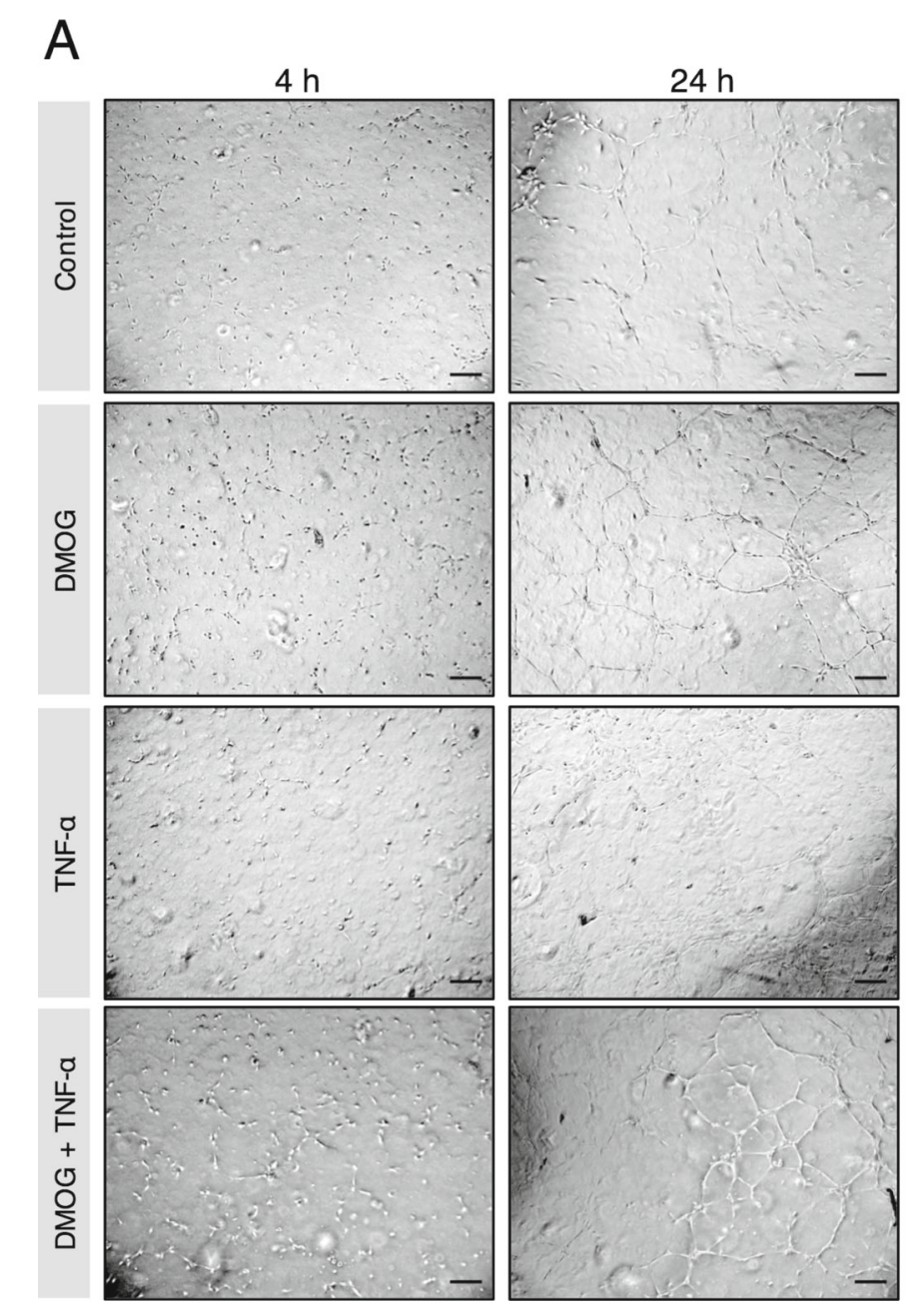

B
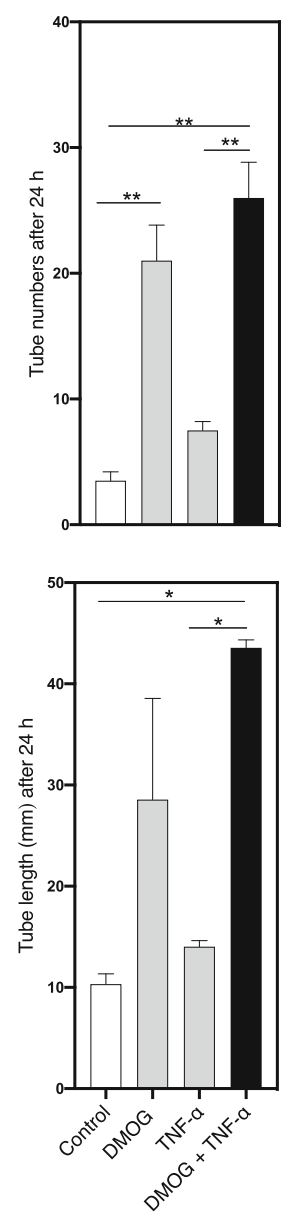

Fig. 9 IPTD-MSC-derived media stimulates endothelial tube formation. a Representative photographs of endothelial cells cultured and treated with medium from conditioned and control IPTD-MSCs at 4 and $24 \mathrm{~h}$ post-culture. Scale bar, $500 \mu \mathrm{m}$. b Quantification is presented as total tube number and total tube length after $24 \mathrm{~h}$. Duplicate samples were performed. Representative microscopic images are presented

for the observed enhancement of endothelial cell tube formation. Upregulation and secretion of pro-angiogenic factors are important for several reasons: (i) MSCs from individuals with diabetes showed lowered angiogenic capacity [52] than those from individuals without diabetes, although another study reported that MSCs isolated from the bone marrow of T1D donors were phenotypically and functionally similar to those isolated from healthy individuals [53]; (ii) treatment of islets with the iron chelator deferoxamine stabilized HIF- $\alpha$ and enhanced islet VEGF levels [54]; and (iii) treatment with exogenous VEGF improves islet engraftment [55] and $\beta$ cell mass [56], in part through increased angiogenesis. Islet survival and function post-transplantation are adversely impacted by hypoxia [57]. Thus, processes that render islets hypoxia-resistant, such as increasing VEGF expression and secretion, should have beneficial effects in islet transplantation. The fact that the combination of DMOG and TNF- $\alpha$ also enhances TSG-6, NRF2, and $V E G F$ gene expression from bone marrow-derived MSCs highlights the potential use of DMOG and TNF- $\alpha$ to condition MSCs other than IPTD-MSCs. Further, the upregulation of TSG-6 in both IPTD-MSCs and bone marrow-derived MSCs underscores the concept of employing TSG-6 as a marker of anti-inflammatory capacity [58].

An interesting finding was the proximity of MSCs to islets within the pancreatic tissue, implying a possible role for these MSCs in protecting islets from metabolic stress and inflammation. Besides the potential anti-inflammatory and pro-angiogenic effects of IPTD-MSCs, future studies will explore whether extracellular vesicles (EV) [59] secreted by these cells are more effective at limiting autoimmune diseases such as T1D and uveoretinitis [60]. 


\section{Conclusion}

In summary, the simultaneous isolation of human islets and intra-pancreatic tissue-derived MSCs was demonstrated. These IPTD-MSCs can be expanded in a clinically applicable culture system and potentiated ex vivo in their anti-inflammatory and pro-angiogenic properties. Such IPTD-MSCs, together with the islets originating from the same donor organ, may enhance islet transplantation outcome and other potential clinical applications.

\section{Abbreviations \\ DMOG: Dimethyloxallyl glycine; hPL: Human platelet lysate; HUVECs: Human

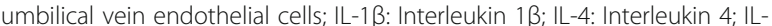 6: Interleukin 6; IL-8: Interleukin 8; IL-10: Interleukin 10; IPTD: Intra-pancreatic tissue-derived; MCP-1: Monocyte chemoattractant protein-1; MMP-2: Matrix metallopeptidase 2; MMP-9: Matrix metallopeptidase 9; MSC: Mesenchymal stromal cell; NRF2: Nuclear factor erythroid 2-related factor 2; T1D: Type 1 diabetes; TSG-6: Tumor necrosis factor alpha-stimulated gene-6; VEGF: Vascular endothelial growth factor}

\section{Acknowledgements}

Human pancreatic islets were provided by the NIDDK-funded Integrated Islet Distribution Program (IIDP) at City of Hope. The authors gratefully acknowledge Ms. Kiran Sriram and Dr. Zhen Chen for technical assistance with the Matrigel tube formation assay. We also extend our thanks to all islet isolation team members at City of Hope. Luminex assays of culture supernatants were performed by staff members of the core facility at the Beckman Research Institute of City of Hope.

\section{Authors' contributions}

BK conducted the experiments; collected, analyzed, and interpreted the data; and wrote the manuscript. MQ and IHA conceived and designed the study collected and or assembled, analyzed, and interpreted the data; and wrote the manuscript. WD, KTC, KVM, and RGP conducted the experiments and collected the data. JSI analyzed and interpreted the data and wrote the manuscript. FK provided the financial support for the study. HTK performed the data analysis and interpretation and wrote the manuscript. All authors read and approved the final manuscript.

\section{Funding}

This study was supported, in part, by the Diabetes and Metabolic Research Institute of City of Hope to F.K. and NIH grant R01DK099734 to H.T.K. Support from the Wanek Family Project of Type 1 Diabetes to F.K. and H.T.K. is also gratefully acknowledged.

\section{Availability of data and materials}

Please contact author for data requests.

\section{Ethics approval and consent to participate}

Research consent for the use of human tissue was obtained from the donor next of kin and ethics approval for this study was granted by the Institutional Review Board of City of Hope (IRB \# 01046). In the case of bone marrow-derived MSCs, consent was obtained from donors and ethics approval for this was granted by the Medical Ethics Board of Leiden University Medical Center.

\section{Consent for publication}

Not applicable.

\section{Competing interests}

$\mathrm{BK}, \mathrm{MQ}, \mathrm{HTK}$, and IHA have patents pending related to this study. The other authors declare that they have no competing interests.

\section{Author details}

${ }^{1}$ Department of Translational Research and Cellular Therapeutics, Diabetes and Metabolism Research Institute, Beckman Research Institute of City of Hope, 1500 E. Duarte Rd, Duarte, CA 91010, USA. ²Department of Diabetes Immunology, Diabetes and Metabolism Research Institute, Beckman Research Institute of City of Hope, Duarte, CA, USA.
Received: 8 April 2019 Revised: 26 September 2019

Accepted: 30 September 2019 Published online: 15 November 2019

\section{References}

1. Roberts I. Mesenchymal stem cells. Vox Sang. 2004;87(Suppl 2):38-41.

2. Olsen TR, Ng KS, Lock LT, et al. Peak MSC-are we there yet? Front Med (Lausanne). 2018:5:178.

3. Abdi R, Fiorina P, Adra CN, et al. Immunomodulation by mesenchymal stem cells: a potential therapeutic strategy for type 1 diabetes. Diabetes. 2008:57: 1759-67.

4. Guan LX, Guan H, Li HB, et al. Therapeutic efficacy of umbilical cord-derived mesenchymal stem cells in patients with type 2 diabetes. Exp Ther Med. 2015;9:1623-30.

5. Liu X, Zheng P, Wang $X$, et al. A preliminary evaluation of efficacy and safety of Wharton's jelly mesenchymal stem cell transplantation in patients with type 2 diabetes mellitus. Stem Cell Res Ther. 2014;5:57.

6. Carlsson PO, Schwarcz E, Korsgren $\mathrm{O}$, et al. Preserved beta-cell function in type 1 diabetes by mesenchymal stromal cells. Diabetes. 2015;64:587-92.

7. Berman DM, Willman MA, Han D, et al. Mesenchymal stem cells enhance allogeneic islet engraftment in nonhuman primates. Diabetes. 2010;59: 2558-68.

8. Yeung TY, Seeberger KL, Kin T, et al. Human mesenchymal stem cells protect human islets from pro-inflammatory cytokines. PLoS One. 2012;7: e38189.

9. Brandhorst $D$, Brandhorst $H$, Acreman $S$, et al. Hypoxia-induced damage in human islets is reduced with the use of mesenchymal stem cellpreconditioned medium. Transplant Proc. 2017:49:2330-2.

10. Lee RH, Pulin AA, Seo MJ, et al. Intravenous hMSCs improve myocardial infarction in mice because cells embolized in lung are activated to secrete the anti-inflammatory protein TSG-6. Cell Stem Cell. 2009:5:54-63.

11. Prockop DJ. Inflammation, fibrosis, and modulation of the process by mesenchymal stem/stromal cells. Matrix Biol. 2016;51:7-13.

12. Oh JY, Roddy GW, Choi H, et al. Anti-inflammatory protein TSG-6 reduces inflammatory damage to the cornea following chemical and mechanical injury. Proc Natl Acad Sci U S A. 2010;107:16875-80.

13. Li S, Vaziri ND, Masuda Y, et al. Pharmacological activation of Nrf2 pathway improves pancreatic islet isolation and transplantation. Cell Transplant. 2015; 24:2273-83.

14. Yagishita $Y$, Uruno A, Chartoumpekis DV, et al. Nrf2 represses the onset of type 1 diabetes in non-obese diabetic mice. J Endocrinol. 2019; 240(3):403-416

15. Milkiewicz M, Pugh CW, Egginton S. Inhibition of endogenous HIF inactivation induces angiogenesis in ischaemic skeletal muscles of mice. J Physiol. 2004;560:21-6.

16. Zhang J, Guan J, Qi X, et al. Dimethyloxaloylglycine promotes the Angiogenic activity of Mesenchymal stem cells derived from iPSCs via activation of the PI3K/Akt pathway for bone regeneration. Int J Biol Sci. 2016;12:639-52.

17. Zuk PA, Zhu M, Mizuno $H$, et al. Multilineage cells from human adipose tissue: implications for cell-based therapies. Tissue Eng. 2001;7:211-28.

18. Arzouni AA, Vargas-Seymour A, Rackham $C L$, et al. Mesenchymal stromal cells improve human islet function through released products and extracellular matrix. Clin Sci (Lond). 2017:131:2835-45.

19. Lavoie JR, Creskey MM, Muradia G, et al. Brief report: elastin microfibril interface 1 and integrin-linked protein kinase are novel markers of islet regenerative function in human multipotent mesenchymal stromal cells. Stem Cells. 2016:34:2249-55.

20. Kayleigh M. Van Megen E-JvtW, Julia Lages Motta, Bernice Dekker, Tatjana Nikolic, Bart O. Roep. Activated mesenchymal stromal cells process and present antigens regulating adaptive immunity. Front Immunol doi: https:// doi.org/10.3389/fimmu.2019.00694 (in press).

21. Williams JT, Southerland SS, Souza J, et al. Cells isolated from adult human skeletal muscle capable of differentiating into multiple mesodermal phenotypes. Am Surg. 1999;65:22-6.

22. Wang YH, Yang ZQ, Zhu SF, et al. Comparative study of methotrexate and human umbilical cord mesenchymal stem cell transplantation in the treatment of rheumatoid arthritis. J Biol Regul Homeost Agents. 2018;32: 599-605.

23. Holan V, Trosan P, Cejka C, et al. A comparative study of the therapeutic potential of mesenchymal stem cells and limbal epithelial stem cells for ocular surface reconstruction. Stem Cells Transl Med. 2015;4:1052-63. 
24. Roubelakis MG, Bitsika V, Zagoura D, et al. In vitro and in vivo properties of distinct populations of amniotic fluid mesenchymal progenitor cells. J Cell Mol Med. 2011;15:1896-913.

25. Zuk PA, Zhu M, Ashjian P, et al. Human adipose tissue is a source of multipotent stem cells. Mol Biol Cell. 2002;13:4279-95.

26. Horwitz EM, Gordon PL, Koo WK, et al. Isolated allogeneic bone marrowderived mesenchymal cells engraft and stimulate growth in children with osteogenesis imperfecta: implications for cell therapy of bone. Proc Natl Acad Sci U S A. 2002;99:8932-7.

27. Lee RH, Yu JM, Foskett AM, et al. TSG-6 as a biomarker to predict efficacy of human mesenchymal stem/progenitor cells (hMSCs) in modulating sterile inflammation in vivo. Proc Natl Acad Sci U S A. 2014;111:16766-71.

28. Qi M, McFadden B, Valiente $L$, et al. Human pancreatic islets isolated from donors with elevated $\mathrm{HbA} 1 \mathrm{c}$ levels: islet yield and graft efficacy. Cell Transplant. 2015:24:1879-86.

29. Khiatah B, Tucker A, Chen KT, et al. Evaluation of collagenase gold plus BP protease in isolating islets from human pancreata. Islets. 2018;10(2):51-59.

30. Qi M, Valiente L, McFadden B, et al. The choice of enzyme for human pancreas digestion is a critical factor for increasing the success of islet isolation. Transplant Direct. 2015;1(4):1-9.

31. van der Garde M, van Pel M, Millan Rivero JE, et al. Direct comparison of Wharton's jelly and bone marrow-derived mesenchymal stromal cells to enhance engraftment of cord blood CD34(+) transplants. Stem Cells Dev. 2015:24:2649-59.

32. van Megen KM, van 't Wout ET, Lages Motta J, et al. Activated mesenchymal stromal cells process and present antigens regulating adaptive immunity. Front Immunol. 2019;10:694

33. Iglesias I, Valiente $L$, Shiang KD, et al. The effects of digestion enzymes on islet viability and cellular composition. Cell Transplant. 2012;21:649-55.

34. Chen Z, Lai TC, Jan YH, et al. Hypoxia-responsive miRNAs target argonaute 1 to promote angiogenesis. J Clin Invest. 2013;123:1057-67.

35. Wagner W, Wein F, Seckinger A, et al. Comparative characteristics of mesenchymal stem cells from human bone marrow, adipose tissue, and umbilical cord blood. Exp Hematol. 2005;33:1402-16.

36. Arzouni AA, Vargas-Seymour A, Nardi N et al. Using Mesenchymal Stromal Cells in Islet Transplantation. Stem Cells Transl Med. 2018;7(8):559-563.

37. Sipp D, Robey PG, Turner L. Clear up this stem-cell mess. Nature. 2018;561: 455-7.

38. Path G, Perakakis N, Mantzoros CS, et al. Stem cells in the treatment of diabetes mellitus - focus on mesenchymal stem cells. Metabolism. 2019;90: $1-15$.

39. Zazzeroni L, Lanzoni G, Pasquinelli G, et al. Considerations on the harvesting site and donor derivation for mesenchymal stem cells-based strategies for diabetes. CellR4 Repair Replace Regen Reprogram; 2017. p. 5.

40. Lo Furno D, Mannino G, Cardile V, et al. Potential therapeutic applications of adipose-derived mesenchymal stem cells. Stem Cells Dev. 2016;25(21):1615-1628.

41. Tan J, Wu W, Xu X, et al. Induction therapy with autologous mesenchymal stem cells in living-related kidney transplants: a randomized controlled trial. JAMA. 2012;307:1169-77.

42. Heiskanen A, Satomaa T, Tiitinen S, et al. N-glycolylneuraminic acid xenoantigen contamination of human embryonic and mesenchymal stem cells is substantially reversible. Stem Cells. 2007;25:197-202.

43. Sundin M, Ringden $O$, Sundberg B, et al. No alloantibodies against mesenchymal stromal cells, but presence of anti-fetal calf serum antibodies, after transplantation in allogeneic hematopoietic stem cell recipients. Haematologica. 2007;92:1208-15.

44. Reinisch A, Bartmann C, Rohde E, et al. Humanized system to propagate cord blood-derived multipotent mesenchymal stromal cells for clinical application. Regen Med. 2007;2:371-82.

45. Schallmoser K, Bartmann C, Rohde E, et al. Human platelet lysate can replace fetal bovine serum for clinical-scale expansion of functional mesenchymal stromal cells. Transfusion (Paris). 2007;47:1436-46.

46. Najar M, Raicevic G, Crompot E, et al. The Immunomodulatory potential of mesenchymal stromal cells: a story of a regulatory network. J Immunother. 2016:39:45-59.

47. Romieu-Mourez R, Francois M, Boivin MN, et al. Cytokine modulation of TLR expression and activation in mesenchymal stromal cells leads to a proinflammatory phenotype. J Immunol. 2009;182:7963-73.
48. Webb AH, Gao BT, Goldsmith ZK, et al. Inhibition of MMP-2 and MMP-9 decreases cellular migration, and angiogenesis in in vitro models of retinoblastoma. BMC Cancer. 2017;17:434.

49. Cohen T, Nahari D, Cerem LW, et al. Interleukin 6 induces the expression of vascular endothelial growth factor. J Biol Chem. 1996;271:736-41.

50. Gopinathan G, Milagre C, Pearce OM, et al. Interleukin-6 stimulates defective angiogenesis. Cancer Res. 2015;75:3098-107.

51. Li A, Dubey S, Varney ML, et al. IL-8 directly enhanced endothelial cell survival, proliferation, and matrix metalloproteinases production and regulated angiogenesis. J Immunol. 2003;170:3369-76.

52. Kim H, Han JW, Lee JY, et al. Diabetic mesenchymal stem cells are ineffective for improving limb ischemia due to their impaired angiogenic capability. Cell Transplant. 2015;24:1571-84.

53. Davies LC, Alm JJ, Heldring N, et al. Type 1 diabetes mellitus donor mesenchymal stromal cells exhibit comparable potency to healthy controls in vitro. Stem Cells Transl Med. 2016;5:1485-95.

54. Bradley B, Prowse SJ, Bauling P, et al. Desferrioxamine treatment prevents chronic islet allograft damage. Diabetes. 1986;35:550-5.

55. Langlois A, Bietiger W, Seyfritz E, et al. Improvement of rat islet viability during transplantation: validation of pharmacological approach to induce VEGF overexpression. Cell Transplant. 2011;20:1333-42.

56. Brissova M, Aamodt $\mathrm{K}$, Brahmachary $\mathrm{P}$, et al. Islet microenvironment, modulated by vascular endothelial growth factor-A signaling, promotes beta cell regeneration. Cell Metab. 2014;19:498-511.

57. Fraker CA, Cechin S, Alvarez-Cubela S, et al. A physiological pattern of oxygenation using perfluorocarbon-based culture devices maximizes pancreatic islet viability and enhances beta-cell function. Cell Transplant. 2013;22:1723-33.

58. Prockop DJ. The exciting prospects of new therapies with mesenchymal stromal cells. Cytotherapy. 2017;19:1-8.

59. Garcia-Contreras M, Brooks RW, Boccuzzi L, et al. Exosomes as biomarkers and therapeutic tools for type 1 diabetes mellitus. Eur Rev Med Pharmacol Sci. 2017:21:2940-56.

60. Shigemoto-Kuroda T, Oh JY, Kim DK, et al. MSC-derived extracellular vesicles attenuate immune responses in two autoimmune murine models: type 1 diabetes and uveoretinitis. Stem Cell Rep. 2017;8:1214-25.

\section{Publisher's Note}

Springer Nature remains neutral with regard to jurisdictional claims in published maps and institutional affiliations.
Ready to submit your research? Choose BMC and benefit from:

- fast, convenient online submission

- thorough peer review by experienced researchers in your field

- rapid publication on acceptance

- support for research data, including large and complex data types

- gold Open Access which fosters wider collaboration and increased citations

- maximum visibility for your research: over $100 \mathrm{M}$ website views per year

At $\mathrm{BMC}$, research is always in progress.

Learn more biomedcentral.com/submission 